\title{
Identification of molecules associated with response to abatacept in patients with rheumatoid arthritis
}

Waka Yokoyama-Kokuryo 1,2,3, Hayato Yamazaki ${ }^{1,2}$, Tsutomu Takeuchi ${ }^{4}$, Koichi Amano $^{5}$, Jun Kikuchi ${ }^{4}$, Tsuneo Kondo ${ }^{5}$, Seiji Nakamura ${ }^{6}$, Ryoko Sakai ${ }^{2,7}$, Fumio Hirano ${ }^{1,2}$, Toshihiro Nanki ${ }^{1,2,8}$, Ryuji Koike ${ }^{1,2}$ and Masayoshi Harigai ${ }^{1,2,7^{*}}$ (i)

\begin{abstract}
Background: Abatacept (ABA) is a biological disease-modifying antirheumatic drug (bDMARD) for rheumatoid arthritis (RA). The aim of this study was to identify molecules that are associated with therapeutic responses to ABA in patients with RA.

Methods: Peripheral blood was collected using a PAX gene Blood RNA kit from 45 bDMARD-naïve patients with RA at baseline and at 6 months after the initiation of ABA treatment. Gene expression levels of responders $(n=27)$ and non-responders $(n=8)$ to ABA treatment among patients with RA at baseline were compared using a microarray. The gene expression levels were confirmed using real-time quantitative polymerase chain reaction (RT-qPCR).

Results: Gene expression analysis revealed that the expression levels of 218 genes were significantly higher and those of 392 genes were significantly lower in the responders compared to the non-responders. Gene ontology analysis of the 218 genes identified "response to type I interferon (IFN)" with 24 type I IFN-related genes. RT-qPCR confirmed that there was a strong correlation between the score calculated using the 24 genes and that using OAS3, MXI, and IFIT3 (type I IFN score) (rho with the type I IFN score 0.981); the type I IFN score was significantly decreased after treatment with ABA in the responders $(p<0.05)$, but not in the non-responders. The receiver operating characteristic curve analysis of the type I IFN score showed that sensitivity, specificity, and AUC (95\% confidence interval) for the responders were $0.82,1.00$, and 0.92 (0.82-1.00), respectively. Further, RT-qPCR demonstrated higher expression levels of BATF2, LAMP3, CD83, CLEC4A, IDO1, IRF7, STAT1, STAT2, and TNFSF10 in the responders, all of which are dendritic cell-related genes or type I IFN-related genes with significant biological implications.
\end{abstract}

Conclusion: Type I IFN score and expression levels of the nine genes may serve as novel biomarkers associated with a clinical response to ABA in patients with RA.

Keywords: Rheumatoid arthritis, Abatacept, Prediction, Microarray, Interferon signature

\footnotetext{
* Correspondence: harigai.masayoshi@twmu.ac.jp

'Department of Rheumatology, Tokyo Medical and Dental University, 1-5-45 Yushima, Bunkyo-ku, Tokyo 113-8519, Japan

${ }^{2}$ Department of Pharmacovigilance, Tokyo Medical and Dental University,

1-5-45 Yushima, Bunkyo-ku, Tokyo 113-8519, Japan

Full list of author information is available at the end of the article
}

C C The Author(s). 2020 Open Access This article is licensed under a Creative Commons Attribution 4.0 International License, which permits use, sharing, adaptation, distribution and reproduction in any medium or format, as long as you give appropriate credit to the original author(s) and the source, provide a link to the Creative Commons licence, and indicate if changes were made. The images or other third party material in this article are included in the article's Creative Commons licence, unless indicated otherwise in a credit line to the material. If material is not included in the article's Creative Commons licence and your intended use is not permitted by statutory regulation or exceeds the permitted use, you will need to obtain permission directly from the copyright holder. To view a copy of this licence, visit http://creativecommons.org/licenses/by/4.0/. The Creative Commons Public Domain Dedication waiver (http://creativecommons.org/publicdomain/zero/1.0/) applies to the data made available in this article, unless otherwise stated in a credit line to the data. 


\section{Background}

Rheumatoid arthritis (RA) is characterized by chronic inflammatory polyarthritis, which leads to the destruction of the joints causing pain and disability [1]. Cytotoxic T lymphocyte-associated antigen 4 immunoglobulin fusion protein (CTLA4-Ig, abatacept (ABA)) is a biological disease-modifying antirheumatic drug (bDMARD) for RA. $\mathrm{T}$ cells are activated by the interaction of HLA class II molecules on antigen-presenting cells (APCs) with a T cell receptor (TCR) on the surface of $\mathrm{T}$ cells in the presence of CD80/86 on APCs and CD28 on T cells. CTLA4-Ig inhibits the activation of $\mathrm{T}$ cells by selectively modulating the CD80/86-CD28 interaction [2]. Abatacept is as efficacious as other bDMARDs in terms of clinical, structural, and functional outcomes [3]. In a recent meta-analysis, it was found that the risk of serious infections in humans was lower for treatments using ABA than that using other bDMARDs [4]. The prediction of therapeutic responses to ABA could considerably help identify patients that can benefit from the treatment.

Whole blood transcriptomic profiling using microarrays has been widely used to investigate the action mechanisms and identifying appropriate biomarkers predicting the efficacy or safety of various drugs or treatment. Microarrays have been applied to some bDMARDs including ABA [59] to realize precision medicine for RA. Although some promising data have been reported, endeavor to develop novel biomarkers is still required. Here, we report the results of our study to identify molecules associated with therapeutic responses of ABA for patients with RA using a microarray.

\section{Methods}

\section{Patients}

A total of 168 RA patients who fulfilled the 2010 American College of Rheumatology/European League Against Rheumatism classification criteria for RA [10] and who received $\mathrm{ABA}$ for the first time were enrolled in this multicenter, prospective cohort study from Keio University, Saitama Medical University and Tokyo Medical and Dental University from June 2010 to December 2012 [11]. Blood samples for the microarray and RT-PCR were collected from 129 of the 168 patients. Forty-five of the 129 patients were bDMARD-naïve, and they were enrolled in this study. All patients had active RA despite the use of conventional synthetic disease-modifying antirheumatic drug (DMARD) for at least 3 months. Treatment efficacy was evaluated using the European League Against Rheumatism (EULAR) response criteria [12]. Patients were observed for 6 months after the initiation of ABA treatment. This study was registered at the University Hospital Medical Information Network Clinical Trials Registry (UMIN000005144). This study was approved by the Ethics Committee of the Tokyo Medical and Dental University Hospital (\#836 and
\#M2015-553-01) and the other participating institutions. All subjects provided written informed consent.

\section{RNA extraction}

Blood from the patients was collected in PAXgene Blood RNA tubes (PreAnalytiX) at baseline and at 6 months after the initiation of ABA treatment. Total RNAs were extracted using PAXgene Blood RNA Kits (PreAnalytiX) following the manufacturer's instructions. The total RNA quantity and quality were determined using a NanoDrop1000 spectrophotometer (Thermo Fisher Scientific) and an Agilent 2100 Bioanalyzer (Agilent Technologies).

\section{Microarray experiment}

Cy3-labeled complementary RNAs (cRNAs) were synthesized using Quick Amp Labeling Kits (Agilent). The cRNAs were hybridized at $65^{\circ} \mathrm{C}$ for $17 \mathrm{~h}$ to Whole Human Genome 44K Microarrays (Agilent, Design ID: 014850). After washing, the microarrays were scanned using an Agilent DNA microarray scanner (Agilent). The intensity values of each scanned feature were quantified using Agilent Feature Extraction Software (Agilent).

\section{Microarray data analysis}

Signal intensity was adjusted using quantile normalization plus ComBat to reduce the batch effect $[13,14]$. After excluding poorly annotated probes and low signal probes (average signal <100), 10,420 probes were extracted for further statistical analysis. We implemented a functional genomic analysis using the PANTHER Overrepresentation Test. The reference list included all Homo sapiens genes, and the annotation dataset was obtained from the GO Ontology database (released November 30, 2016).

Real-time quantitative polymerase chain reaction analysis Real-time qPCR (RT-qPCR) analysis was performed using a Custom RT2 Profiler PCR Array (QIAGEN) and RT2 qPCR Primer Assays (QIAGEN) according to the manufacturer's instructions. cDNA was generated using $400 \mathrm{ng}$ of total RNA. Real-time PCR was performed with a Roche Lightcycler 480 (Roche Diagnostics) using 4 ng cDNA per reaction. The thermal profile was as follows: denaturation $\left(95^{\circ} \mathrm{C}, 1 \mathrm{~min}\right)$ and amplification $\left(45\right.$ cycles; $95^{\circ} \mathrm{C}, 15 \mathrm{~s}$; $\left.60{ }^{\circ} \mathrm{C}, 1 \mathrm{~min}\right)$. The second derivative maximum method was used to determine the crossing point $(\mathrm{Cp})$ values. The relative expression of the targeting gene was normalized to $18 \mathrm{~S}$ rRNA (QIAGEN).

\section{Statistical analysis}

The primary objective of this study was to identify novel molecules associated with therapeutic responses to ABA for patients with RA, and the secondary objective was validation of the results of the previous study [9]. Fisher's exact test and Student's $t$ test were used to compare the 
categorical and continuous variables between two groups, respectively. The differences in gene expression at baseline obtained using the microarray and RT-qPCR were analyzed using the Welch's $t$ tests; $p<0.05$ was considered statistically significant. The type I IFN score was calculated using the $Z$-score methods [15]. Correlation between the IFN signature with 24 genes and that with a smaller number of genes was analyzed by Spearman's correlation test. The optimal cut-off value for discriminating the responders and non-responders to ABA treatment were determined by receiver operating characteristic curve (ROC) analysis.

\section{Results}

\section{Clinical characteristics of the patients at baseline}

Of the 45 bDMARD-naive patients with RA from whom blood sample for microarray research was obtained, 27 were classified as good responders (described as responders hereafter, $60.0 \%$ ); 10 , as moderate responders (22.2\%); and 8, as non-responders (17.8\%) using EULAR response criteria [12]. In order to extract responseassociated molecules efficiently, we compared baseline data of the responders and non-responders (Table 1). There was no significant difference in age, sex, prevalence of rheumatoid factor and anti-cyclic citrullinated peptide $(\mathrm{CCP})$ antibody, disease activity, and the use of prednisolone (PSL) between the two groups. For the responder group, the disease duration tended to be longer and methotrexate (MTX) was used more frequently.

Genes associated with clinical response to $A B A$ treatment To identify novel biomarkers associated with clinical responses to ABA treatment, we compared gene expression levels at baseline between the responders and the nonresponders. The expression levels of 218 genes in the responders was significantly higher than that of the nonresponders, and the expression levels of 392 genes in the responders was significantly lower than that of the nonresponders $(p<0.05$, false discovery rate $(\mathrm{FDR})<0.333$ and fold change >1.3) (Supplementary data 1). Gene ontology (GO) analysis of the 218 genes identified "response to type I interferon (IFN) (GO:0034340)" with 24 type I IFN-related genes: BST2, GBP2, IFI27, IFI35, IFI6, IFIT1, IFIT2, IFIT3, IFITM1, IFITM3, IRF7, ISG15, ISG20, MX1, MX2, OAS1, OAS2, OAS3, OASL, RSAD2, STAT1, STAT2, TRIM56, and XAF1 [16]. Twelve out of the 24 type I IFN-related genes were elevated $(p<0.05$ without conditions of FDR or fold changes) in the responders compared to the moderate responders plus nonresponders $(n=18)$ (Supplementary Table 1 and Supplementary data 2) and the GO analysis again identified "response to type I interferon (IFN)." The GO analysis of the 392 genes downregulated in the responders did not identify a specific group of genes. The previously reported genes associated with therapeutic response to ABA, which were elongation arrest and recovery-related genes and CD56-specifically expressed genes [9], were not included in the over- or under-expressed genes.

\section{Type I IFN score and treatment response to ABA}

To evaluate the association of the type I IFN signature and treatment response to ABA, we calculated the type I IFN score using the average values of the $Z$-scored 24 type I IFN genes, as reported by Kennedy et al. [15]. The type I IFN score of the responders was significantly higher than the non-responders $(p<0.005$, Fig. 1). In

Table 1 Clinical characteristics of responders and non-responders at baseline

\begin{tabular}{|c|c|c|c|}
\hline & Responders & Non-responders & $p$ value \\
\hline Number of patients & 27 & 8 & \\
\hline Age, year & $59.4 \pm 13.1$ & $67.4 \pm 12.5$ & N.S. \\
\hline Female, $n(\%)$ & $22(81.5)$ & $5(62.5)$ & N.S. \\
\hline Disease duration, month & $109.2 \pm 147.9$ & $50.25 \pm 56.7$ & N.S. \\
\hline RF titer, $\mathrm{mg} / \mathrm{dl}$ & $69.7 \pm 78.3(n=26)$ & $83.5 \pm 74.3$ & N.S. \\
\hline RF positivity, $n(\%)$ & $20(76.9)$ & $8(100)$ & N.S. \\
\hline Anti-CCP antibody titer, $\mathrm{U} / \mathrm{ml}$ & $92.8 \pm 94.0(n=25)$ & $120.7 \pm 117$ & N.S. \\
\hline Anti-CCP antibody positivity, $n(\%)$ & 25 (91.6) & $8(100)$ & N.S. \\
\hline DAS28-CRP & $4.37 \pm 1.04$ & $3.81 \pm 0.98$ & N.S. \\
\hline Use of PSL, $n(\%)$ & $5(18.5)$ & $3(37.5)$ & N.S. \\
\hline PSL dose, mg/day & $6.4 \pm 5.0$ & $10.25 \pm 7.2$ & N.S. \\
\hline Use of MTX, $n(\%)$ & $19(70.0)$ & $2(25.0)$ & 0.04 \\
\hline MTX dose, mg/week & $10.61 \pm 3.7$ & $9.0 \pm 4.2$ & N.S. \\
\hline
\end{tabular}

Values are expressed as the mean \pm SD. Fisher's exact test and Student's $t$ test were used to compare categorical and continuous variables between the two groups, respectively. $p<0.05$ was considered statistically significant

N.S. not significant, $R F$ rheumatoid factor, $C C P$ cyclic citrullinated peptide, DAS28-CRP disease activity score in 28 joints using C-reactive protein, PSL prednisolone, MTX methotrexate 


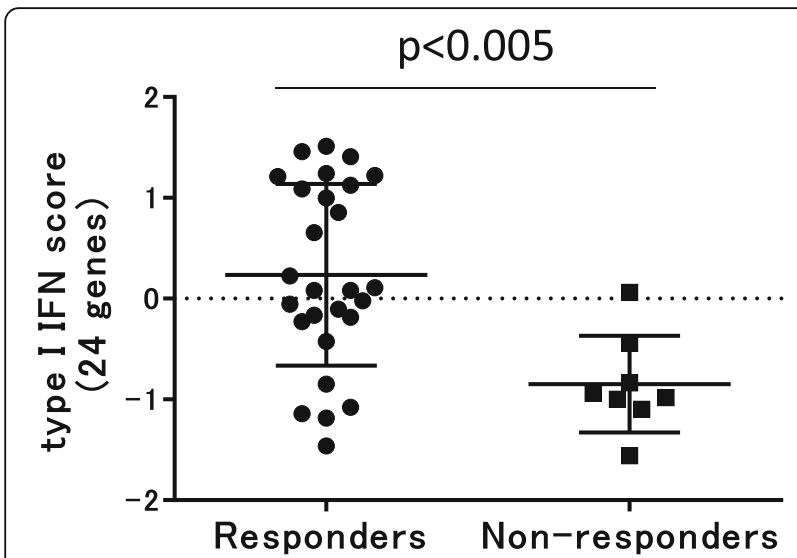

Fig. 1 Comparison of type I IFN scores between responders and non-responders. Type I IFN score was calculated using the average values of the Z-scored 24 type I IFN genes, as reported by Kennedy et al. [15]. Responders to abatacept showed higher type I IFN score than non-responders ( $p<0.005$, the Mann-Whitney's $U$ test)

order to reproduce the type I IFN score with fewer genes, we compared the type I IFN score calculated using the 24 genes and the scores created by a combination of some of the genes (Supplementary Fig. 1A). We found that there was a strong correlation between the scores calculated by the 24 genes and the score created using genes of OAS3, MX1, and IFIT3 (rho with the type I IFN score 0.981) (designated as type I IFN score hereafter) (Supplementary Fig. 1B).

To confirm the expression levels of genes using the microarray analysis and their association with the treatment response to ABA, we performed RT-qPCR; we quantified the expression levels of $O A S 3, M X 1$, and IFIT3 to calculate the type I IFN score using the same RNA samples used for microarray analysis. The type I IFN score using RT-qPCR of the responders was significantly higher than that of the non-responders $(p<$ 0.0005, Fig. 2). We also compared the type I IFN score at baseline and at 24 weeks after the initiation of ABA treatment. The type I IFN score using RT-qPCR significantly decreased, albeit only a $15 \%$ reduction, after treatment with $\mathrm{ABA}$ in the responders $(p<0.05$, Fig. 2); however, this was not observed for the non-responders.

The ROC analysis revealed an optima cutoff value of the relative expression levels as -0.565 . Sensitivity, specificity, and AUC (95\% confidence interval) were 0.82, 1.00, and 0.92 (0.82-1.00), respectively (Supplementary Fig. 2).

\section{Other treatment response-associated molecules confirmed by RT-qPCR}

Since type I IFN is primarily produced by plasmacytoid dendritic cells (pDC), we selected dendritic cell-related genes or type I IFN-related genes with significant biological implications for quantification using RT-qPCR among the 218 genes as follows: BATF2, LAMP3, and

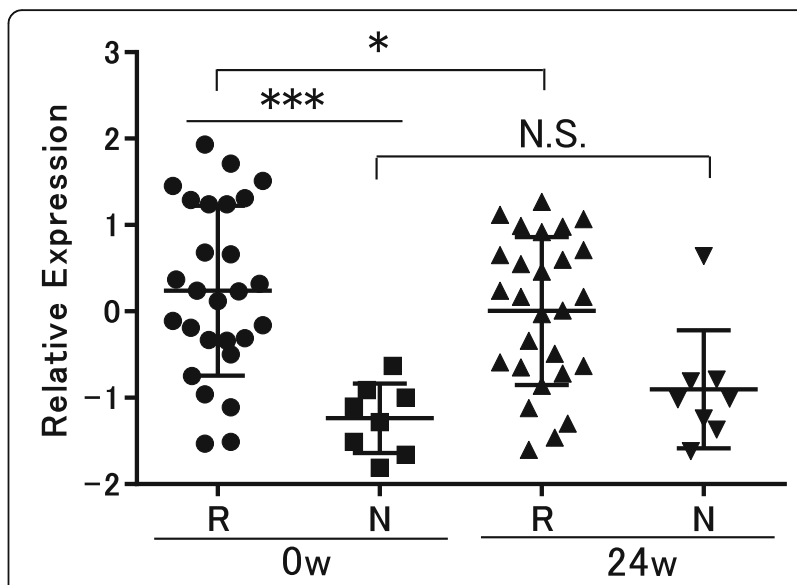

Fig. 2 Type I IFN score using RT-qPCR at baseline and 24 weeks after the initiation of abatacept treatment. The expression levels of OAS3, MX1, and IFIT3 were determined by using RT-qPCR to calculate the type I IFN score for the same RNA samples of microarray analysis (Fig. 2). $p<0.05$ was considered statistically significant. ${ }^{*} p<0.05$, ${ }^{* *} p<0.01,{ }^{* * *} p<0.001$. R, responders; N, non-responders; N.S. not significant

$C D 83$ are related to dendritic cell activation and maturation [17-19]; TNFSF10, BTLA, and IDO1 are expressed on dendritic cells (DCs) [20-24]. CLEC4A has a role in the production of type I IFN from pDC [25], and STAT1, STAT2, and IRF7 have roles in the signal of type I IFN production [26-28]. The expression levels of these 10 genes measured by qRT-PCR in the responders were significantly higher compared to those of the nonresponders except for BTLA (Fig. 3). We compared gene expression levels among patients with different disease activities at baseline and 24 weeks after the initiation of ABA treatment, and it found that all genes had no association with the disease activities at both time points (data not shown).

We compared the expression levels of these 10 genes before and after treatment with ABA using RT-qPCR. The expressions of LAMP3 and STAT1 were significantly decreased after treatment with ABA; however, the percentage of reduction was relatively small (LAMP $41.7 \%$ and STAT1 17.4\%, Fig. 3b, g).

\section{Discussion}

In this study, we demonstrated that the type I IFN score and the expression levels of BATF2, LAMP3, CD83, CLEC4A, IDO1, IRF7, STAT1, STAT2, and TNFSF10 are associated with a good clinical response to ABA in patients with RA.

The family of type I IFNs, which consist of IFN-alpha and IFN-beta, has an important role in regulating immune response [28] [29]. The high expression of the type I IFN signature was found in 22 to $65 \%$ of the patients with RA $[27,30]$ but was not associated with disease activity [31]. It 


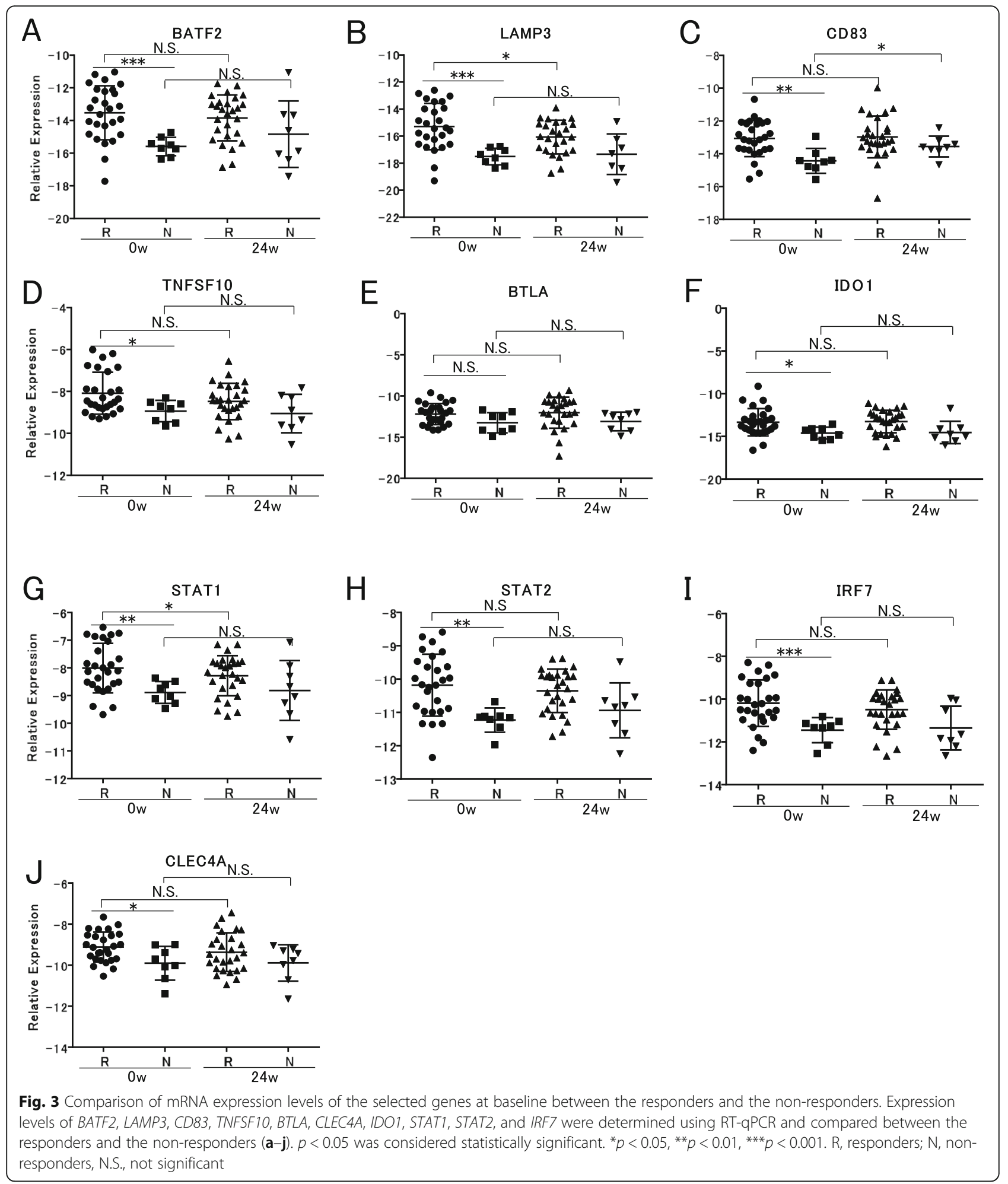

has been reported that the type I IFN signature is highly expressed in the pre-clinical phase of RA with increased levels of anti-CCP antibody and rheumatoid factor [32, 33]. In addition, IFN-administered patients often develop arthritis as an adverse drug reaction [34-36], which indicates that the increased levels of type I IFN, triggered by a viral infection or other immunological stimuli, may be involved in the pathogenesis of pre-clinical or early RA. It is reported that arthritis was mitigated in interferon alpha/beta receptor alpha chain-deficient mice and 
interferon regulatory factor-1-deficient mice [37, 38]. These reports together with our data may indicate that ABA shows its clinical efficacy through the reduction of the type I IFN activity in patients with RA.

The expression levels of genes related to the activation of dendritic cells, BATF2, LAMP3, and CD83, showed significant differences between responders and nonresponders at baseline. LAMP3 was one of the differentially expressed genes between RA and osteoarthritis patients [39], and CD83 was expressed in more than $20 \%$ of pDCs in the RA synovium [40]. In addition, early-stage RA patients had elevated levels of soluble CD83 in plasma [41]. Since $C D 83$ is expressed as a membrane-bound form on mature dendritic cells and as a soluble form in plasma, further studies are warranted to evaluate the predictive ability of CD83 mRNA or proteins for responses to ABA treatment or to other treatments in patients with RA.

Comparing the background at the start of ABA treatment, the percentage of MTX users was different in responders and non-responders. Recently, it has been reported that the expression level of the type 1 IFN is higher in patients that do not respond to methotrexate [42]. As there was no difference in the type I IFN scores among MTX users and non-users in both responders and non-responders in this study (data not shown), the cause of the difference in type I IFN expressions between the responders and the non-responders is not attributed to the percentage of MTX use.

This study has some limitations. First is the small sample size. The association of IFN signature with therapeutic response to ABA identified between responders $(n=27)$ and non-responders $(n=8)$ was supported by the comparison between the responders vs moderate- plus no-responders $(n=18)$. Second, we did not have validation cohort, and the risk of over-fitting of models should be considered. Our results need to be confirmed in a future study. Third, we could not validate the results of the previous study, in which the signature scores of elongation arrest and recovery-related genes, and CD56-specifically expressed genes were significantly elevated in non-responders [9]. The characteristics of the patient population analyzed and the definition of therapeutic response applied may account for the difference between the studies.

\section{Conclusion}

Type I IFN score and expression levels of the nine genes-BATF2, LAMP3, CD83, TNFSF10, CLEC4A, IDO1, STAT1, STAT2, and IRF7-may serve as biomarkers for predicting the clinical responses to ABA treatment in patients with RA.

\section{Supplementary information}

Supplementary information accompanies this paper at https://doi.org/10. 1186/s13075-020-2137-y.
Additional file 1: Figure S1A, B. Correlation between the IFN signature with 24 genes and the IFN signature with a smaller number of genes from the 24 genes. Figure S2. The receiver operating characteristics curve of the type I IFN score for the responders. (PPTX $65 \mathrm{~kb}$ )

Additional file 2: Table S1. Clinical characteristics of EULAR responders vs moderate and non-responders at baseline.

Additional file 3. List of genes with higher and lower expression levels in EULAR good responders compared to non-responders.

Additional file 4. List of genes with higher and lower expression levels in EULAR good responders compared to moderate and non-responders.

\section{Abbreviations}

ABA: Abatacept; APCs: Antigen-presenting cells; bDMARDs: Biological disease-modifying antirheumatic drugs; CCP: Cyclic citrullinated peptide; CSDMARD: Conventional synthetic DMARD; DMARD: Disease-modifying antirheumatic drug; EULAR: The European League Against Rheumatism; FDR: False discovery rate; GO: Gene ontology; IFN: Interferon; IFX: Infliximab; MTX: Methotrexate; PSL: Prednisolone; RA: Rheumatoid arthritis; RTQPCR: Real-time quantitative polymerase chain reaction; RTX: Rituximab; TCR: T cell receptor

\section{Acknowledgements}

Supported in part by Grants-in-Aid for Scientific Research from the Ministry of Education, Culture, Sports, Science, and Technology of Japan, GCOE Program, International Research Center for Molecular Science in Tooth and Bone Diseases at Tokyo Medical and Dental University, Grants-in-Aid for Scientific Research, KAKENHI, and a research grant from the Ministry of Health, Labour and Welfare. We thank Dr. Yoshiro Fujita for his helpful discussions and Marie Kokido for her excellent secretarial support. We would like to thank Editage (www.editage.com) for English language editing.

\section{Authors' contributions}

WY-K participated in the design of the study, carried out the experiments and statistical analysis, and drafted the manuscript. YH, KA, TT, JK, TK, RS, FH, RK, TN, and MH collected data and blood samples, assisted carrying out the experiments, and provided a critical review of the manuscript. SN performed microarray experiments and analyzed the data, and SN also provided a critical review of the manuscript. MH conceived the study, participated in its design and coordination, and helped draft the manuscript. All authors read and approved the final manuscript.

\section{Funding}

This work was supported by unrestricted research grants to the Department of Pharmacovigilance, Tokyo Medical and Dental University, and to the Division of Epidemiology and Pharmacoepidemiology, Department of Rheumatology,

School of Medicine, Tokyo Women's Medical University, Grants-in-Aid for Scientific Research, KAKENHI (\#15 K19570), and a research grant from the Ministry of Health, Labour and Welfare (H30-meneki-shitei-002).

\section{Availability of data and materials}

The datasets generated and/or analyzed during the current study are not publicly available due to future analysis plans but are available upon request under the condition of collaboration.

\section{Ethics approval and consent to participate}

The protocol was approved by the Institutional Review Board of Tokyo Medical and Dental University (\#836, \#115, and \#M2015-553) and by the respective boards of other participating institutions. Written informed consent was obtained from each patient. The study was performed in compliance with ethical guidelines for epidemiological research in Japan and the Helsinki Declaration (revised in 2008).

\section{Consent for publication}

Not applicable.

\section{Competing interests}

WY-K received honoraria from Eisai Co., Ltd., Asahikasei Pharma Corp. HY is currently an employee of Nippon Boehringer Ingelheim Co., Ltd. TT received Grants from Astellas Pharma Inc., Chugai Pharmaceutical Co, Ltd., Daiichi 
Sankyo Co., Ltd., Takeda Pharmaceutical Co., Ltd., AbbVie GK, Asahikasei Pharma Corp., Mitsubishi Tanabe Pharma Co., Pfizer Japan Inc., Eisai Co., Ltd., AYUMI Pharmaceutical Corporation, Nipponkayaku Co. Ltd., and Novartis Pharma K.K. TT received personal fees from AbbVie GK., Astellas Pharma Inc., Astra Zeneca K.K., Bristol-Myers K.K., Chugai Pharmaceutical Co. Ltd., Diaichi Sankyo Co. Ltd., Eisai Co. Ltd., Eli Lilly Japan K.K., GlaxoSmithKline K.K., Janssen Pharmaceutical K.K., Mitsubishi Tanabe Pharma Co., Nipponkayaku Co., Ltd., Novartis Pharma K.K., Pfizer Japan Inc., Sanofi K.K., Teijin Pharma Ltd., Taiho Pharmaceutical Co. Ltd., Taisho Pharmaceutical Co. Ltd., Takeda Pharmaceutical Co. Ltd., and UCB Japan Co. Ltd. KA received honoraria from Chugai Pharmaceutical Co. Ltd., Eli Lilly Japan K.K., Pfizer Japan Inc., and Mitsubishi Tanabe Pharma and the research grant from Chugai Pharmaceutical Co. Ltd. and Asahi Kasei Pharma. JK received honoraria from Astellas Pharma Inc., Chugai Pharmaceutical Co., Ltd., Mitsubishi Tanabe Pharma Co., Pfizer Japan Inc., Eisai Co., Ltd., Bristol-Myers K.K., Eli Lilly Japan K.K., GlaxoSmithKline K.K., Janssen Pharmaceutical K.K., and Sanofi K.K.

Tokyo Medical and Dental University (TMDU) received unrestricted research grants for Department of Pharmacovigilance from AbbVie Japan Co., Ltd., Astellas Pharma Inc., Bristol-Myers Squibb K.K., Chugai Pharmaceutical Co. Ltd., Eisai Co., Ltd., Mitsubishi Tanabe Pharma Co., Ono Pharmaceuticals, Pfizer Japan Inc., Sanofi-Aventis K.K., Santen Pharmaceutical Co., Ltd., Takeda Pharmaceutical Co., Ltd., and UCB Japan, with which TMDU paid the salaries of HY, RS, TN, and MH. The Department of Lifetime Clinical Immunology of Tokyo Medical and Dental University (TMDU) has received unrestricted research grants from Chugai Pharmaceutical Co, Ltd: Ono Pharmaceuticals; Mitsubishi Tanabe Pharma Co.; UCB Japan; CSL Behring; Towa Pharmaceutical Co., Ltd.; Abbvie Japan Co., Ltd.; Japan Blood Products Organization; Ayumi Pharmaceutical Co.; and Nippon Kayaku Co., Ltd., with which TMDU currently pays the salary of FH. FH also received consulting fees from Ono Pharmaceuticals, Astellas Pharma Inc., Sumitomo Dainippon Pharma, and Chugai Pharmaceutical Co., Ltd.

SN, TK, and RK have nothing to declare.

\section{Author details}

'Department of Rheumatology, Tokyo Medical and Dental University, 1-5-45 Yushima, Bunkyo-ku, Tokyo 113-8519, Japan. ${ }^{2}$ Department of Pharmacovigilance, Tokyo Medical and Dental University, 1-5-45 Yushima, Bunkyo-ku, Tokyo 113-8519, Japan. ${ }^{3}$ Department of Rheumatology, Japan Organization of Occupational Health and Safety Chubu Rosai Hospital, 1-10-6 Koumei, Minato-ku, Nagoya-City, Aichi, Japan. ${ }^{4}$ Division of Rheumatology, Department of Internal Medicine, Keio University School of Medicine, 35 Shinanomachi, Shinjuku-ku, Tokyo 160-8582, Japan. ${ }^{5}$ Department of Rheumatology and Clinical Immunology, Saitama Medical Center, Saitama Medical University, 1981 Kamoda, Kawagoe-shi, Saitama 350-8550, Japan. ${ }^{6}$ DNA Chip Research Inc, 1-15-1 Kaigan, Minato-ku, Tokyo 105-0022, Japan. ${ }^{7}$ Department of Rheumatology, Tokyo Women's Medical University School of Medicine, 8-1 Kawada-cho, Shinjuku-ku, Tokyo 162-8666, Japan. ${ }^{8}$ Division of Rheumatology, Department of Internal Medicine, Toho University School of Medicine, 6-11-1 Omori-Nishi, Ota-ku, Tokyo 143-8541, Japan.

\section{Received: 26 August 2019 Accepted: 21 February 2020}

\section{Published online: 12 March 2020}

\section{References}

1. Pincus T, Callahan LF, Sale WG, Brooks AL, Payne LE, Vaughn WK. Severe functional declines, work disability, and increased mortality in seventy-five rheumatoid arthritis patients studied over nine years. Arthritis Rheum. 1984; 27:864-72.

2. Moreland LW, Alten R, Van den Bosch F, Appelboom T, Leon M, Emery P, et al. Costimulatory blockade in patients with rheumatoid arthritis: a pilot, dose-finding, double-blind, placebo-controlled clinical trial evaluating CTLA$4 \mathrm{lg}$ and LEA29Y eighty-five days after the first infusion. Arthritis Rheum. 2002:46:1470-9.

3. Smolen JS, Aletaha D, Barton A, Burmester GR, Emery P, Firestein GS, et al. Rheumatoid arthritis. Nat Rev Dis Prim. 2018:4:18001.

4. Singh JA, Wells GA, Christensen R, Tanjong Ghogomu E, Maxwell $L$, Macdonald JK, et al. Adverse effects of biologics: a network meta-analysis and Cochrane overview. Cochrane Database Syst Rev. 2011;16:CD008794.

5. Serikawa KA, Jacobsen S, Lundsgaard D, Fox BA, Hummelshoj L, Poulsen LK, et al. Detection of gene expression signatures related to underlying disease and treatment in rheumatoid arthritis patients. Mod Rheumatol. 2013;23: 729-40.

6. van Baarsen LG, Wijbrandts CA, Rustenburg F, Cantaert T, van der Pouw Kraan TC, Baeten DL, et al. Regulation of IFN response gene activity during infliximab treatment in rheumatoid arthritis is associated with clinical response to treatment. Arthritis Res Ther. 2010;12:R11.

7. Raterman HG, Vosslamber S, de Ridder S, Nurmohamed MT, Lems WF, Boers $\mathrm{M}$, et al. The interferon type I signature towards prediction of non-response to rituximab in rheumatoid arthritis patients. Arthritis Res Ther. 2012;14:R95.

8. Sellam J, Marion-Thore S, Dumont F, Jacques S, Garchon H-J, Rouanet S, et al. Use of whole-blood transcriptomic profiling to highlight several pathophysiologic pathways associated with response to rituximab in patients with rheumatoid arthritis: data from a randomized, controlled, open-label trial. Arthritis Rheumatol. 2014;66:2015-25.

9. Nakamura S, Suzuki K, lijima H, Hata $Y$, Lim CR, Ishizawa $Y$, et al. Identification of baseline gene expression signatures predicting therapeutic responses to three biologic agents in rheumatoid arthritis: a retrospective observational study. Arthritis Res Ther. 2016;18:159.

10. Aletaha D, Neogi T, Silman AJ, Funovits J, Felson DT, Bingham CO, et al. 2010 rheumatoid arthritis classification criteria: an American College of Rheumatology/European League Against Rheumatism collaborative initiative. Arthritis Rheum. 2010;62:2569-81.

11. Yamazaki H, Hirano F, Takeuchi T, Amano K, Kikuchi J, Kihara M, et al. Simplified Disease Activity Index remission at month 6 is an independent predictor of functional and structural remissions at month 12 during abatacept treatment in patients with rheumatoid arthritis: a multi-center, prospective cohort study in Japan. Mod Rheumatol. 2017;27:787-94.

12. van Gestel $A$ M, Prevoo ML, van 't Hof M A, van Rijswijk MH, van de Putte LB, van Riel PL. Development and validation of the European League Against Rheumatism response criteria for rheumatoid arthritis. Comparison with the preliminary American College of Rheumatology and the World Health Organization/International League Against Rheumatism Cri. Arthritis Rheum. 1996;39:34-40.

13. Bolstad BM, Irizarry R, Astrand M, Speed TP. A comparison of normalization methods for high density oligonucleotide array data based on variance and bias. Bioinformatics. 2003;19:185-93.

14. Johnson WE, Li C, Rabinovic A. Adjusting batch effects in microarray expression data using empirical Bayes methods. Biostatistics. 2007:8:118-27.

15. Kennedy WP, Maciuca R, Wolslegel K, Tew W, Abbas AR, Chaivorapol C, et al. Association of the interferon signature metric with serological disease manifestations but not global activity scores in multiple cohorts of patients with SLE. Lupus Sci Med. 2015;2:e000080.

16. Ashburner M, Ball CA, Blake JA, Botstein D, Butler H, Cherry JM, et al. Gene ontology: tool for the unification of biology. Nat Genet. 2000;25:25-9.

17. De Saint-Vis B, Vincent J, Vandenabeele S, Vanbervliet B, Pin JJ, Ait-Yahia S, et al. A novel lysosome-associated membrane glycoprotein, DC-LAMP, induced upon DC maturation, is transiently expressed in MHC class II compartment. Immunity. 1998;9:325-36.

18. Tussiwand R, Lee W-L, Murphy TL, Mashayekhi M, KC W, Albring JC, et al. Compensatory dendritic cell development mediated by BATF-IRF interactions. Nature. 2012;490:502-507.

19. Stein MF, Blume K, Heilingloh CS, Kummer M, Biesinger B, Sticht $H$, et al. CD83 and GRASP55 interact in human dendritic cells. Biochem Biophys Res Commun. 2015;459:42-8

20. Fanger NA, Maliszewski CR, Schooley K, Griffith TS. Human dendritic cells mediate cellular apoptosis via tumor necrosis factor-related apoptosisinducing ligand (TRAIL). J Exp Med. 1999;190:1155-64.

21. Kalb ML, Glaser A, Stary G, Koszik F, Stingl G. TRAIL+ human plasmacytoid dendritic cells kill tumor cells in vitro: mechanisms of imiquimod- and IFN-mediated antitumor reactivity. J Immunol. 2012;188:1583-91.

22. Simon T, Bromberg JS. BTLA + dendritic cells: the regulatory $T$ cell force awakens. Immunity. 2016;45:956-8.

23. Tu L, Chen J, Zhang H, Duan L. Interleukin-4 inhibits regulatory $T$ cell differentiation through regulating CD103+ dendritic cells. Front Immunol. 2017;8:214.

24. Prendergast GC, Malachowski WP, DuHadaway JB, Muller AJ. Discovery of IDO1 inhibitors: from bench to bedside. Cancer Res. 2017;77:6795-811.

25. Meyer-Wentrup F, Benitez-Ribas D, Tacken PJ, Punt CJA, Figdor CG, de Vries IJM, et al. Targeting DCIR on human plasmacytoid dendritic cells results in antigen presentation and inhibits IFN-alpha production. Blood. 2008;111: 4245-53. 
26. Honda K, Yanai H, Negishi H, Asagiri M, Sato M, Mizutani T, et al. IRF-7 is the master regulator of type-l interferon-dependent immune responses. Nature Nature Publishing Group. 2005;434:772-7.

27. Rodriguez-Carrio J, Lopez P, Suarez A. Type I IFNs as biomarkers in rheumatoid arthritis: towards disease profiling and personalized medicine. Clin Sci. 2015;128:449-64.

28. Honda K. Regulation of the type I IFN induction: a current view. Int Immunol. 2005;17:1367-78.

29. Theofilopoulos AN, Baccala R, Beutler B, Kono DH. Type I Interferons (A/B) in immunity and autoimmunity. Annu Rev Immunol. 2005;23:307-35.

30. Reynier F, Petit F, Paye M, Turrel-Davin F, Imbert PE, Hot A, et al. Importance of correlation between gene expression levels: application to the type i interferon signature in rheumatoid arthritis. PLoS One. 2011;6:1-8.

31. Cantaert T, van Baarsen LG, Wijbrandts CA, Thurlings RM, van de Sande MG, Bos $C$, et al. Type I interferons have no major influence on humoral autoimmunity in rheumatoid arthritis. Rheumatology. 2010;49:156-66.

32. Lübbers J, Brink $M$, van de Stadt LA, Vosslamber S, Wesseling JG, van Schaardenburg D, et al. The type I IFN signature as a biomarker of preclinical rheumatoid arthritis. Ann Rheum Dis. 2013;72:776-80.

33. Castañeda-Delgado JE, Bastián-Hernandez Y, Macias-Segura N, SantiagoAlgarra D, Castillo-Ortiz JD, Alemán-Navarro AL, et al. Type I interferon gene response is increased in early and established rheumatoid arthritis and correlates with autoantibody production. Front Immunol. 2017;8:285.

34. Johnson DM, Hayat SQ, Burton GV. Rheumatoid arthritis complicating adjuvant interferon-alpha therapy for malignant melanoma. J Rheumatol. 1999;26:1009-10.

35. Ionescu C, Micu L, Constantinescu I, Hortopan M, Ursaciuc C, Voiculescu M. Prolonged treatment with interferon alpha and peginterferon induces rheumatoid arthritis syndrome and erythema nodosum. J Gastrointestin Liver Dis. 2008;17:211-2.

36. Passos de Souza E, Evangelista Segundo PT, José FF, Lemaire D, Santiago M. Rheumatoid arthritis induced by alpha-interferon therapy. Clin Rheumatol. 2001:20:297-9

37. Magnusson M, Zare F, Tarkowski A. Requirement of type I interferon signaling for arthritis triggered by double-stranded RNA. Arthritis Rheum. 2006;54:148-57.

38. Tada Y, Ho A, Matsuyama T, Mak TW. Reduced incidence and severity of antigen-induced autoimmune diseases in mice lacking interferon regulatory factor-1. J Exp Med. 1997:185:231-8.

39. Li WC, Bai DL, Xu Y, Chen H, Ma R, Hou WB, et al. Identification of differentially expressed genes in synovial tissue of rheumatoid arthritis and osteoarthritis in patients. J Cell Biochem. 2019;120:4533-44.

40. Lebre MC, Jongbloed SL, Tas SW, Smeets TJM, Mclnnes IB, Tak PP. Rheumatoid arthritis synovium contains two subsets of CD83-DC-LAMPdendritic cells with distinct cytokine profiles. Am J Pathol. 2008;172:940-50

41. Kristensen A-M, Stengaard-Pedersen K, Hetland ML, Hørslev-Petersen K, Junker $P$, Østergaard $M$, et al. Expression of soluble CD83 in plasma from early-stage rheumatoid arthritis patients is not modified by anti-TNF-a therapy. Cytokine. 2017;96:1-7.

42. Plant D, Maciejewski M, Smith S, Nair N, Hyrich K, Ziemek D, et al. Profiling of gene expression biomarkers as a classifier of methotrexate nonresponse in patients with rheumatoid arthritis. Arthritis Rheumatol. 2019;71:678-84.

\section{Publisher's Note}

Springer Nature remains neutral with regard to jurisdictional claims in published maps and institutional affiliations.

Ready to submit your research? Choose BMC and benefit from:
- fast, convenient online submission
- thorough peer review by experienced researchers in your field
- rapid publication on acceptance
- support for research data, including large and complex data types
- gold Open Access which fosters wider collaboration and increased citations
- maximum visibility for your research: over 100M website views per year
At BMC, research is always in progress.
Learn more biomedcentral.com/submissions

